\title{
Sahel droughts and ENSO dynamics
}

\author{
Serge Janicot \\ Météo-France, Laboratoire de Météorologie Dynamique du CNRS, Palaiseau, France
}

\author{
Vincent Moron, Bernard Fontaine \\ Centre de Recherche de Climatologie, Université de Bourgogne, Dijon, France
}

\begin{abstract}
Correlations between summer Sahel rainfall and Southern Oscillation Index has increased during the last thirty years. At high frequency time scale (periods lower than 8 years), an intertropical Atlantic zonal divergent circulation anomaly is forced by the difference of sea surface temperature (SST) anomalies between the eastern equatorial parts of Pacific and Atlantic. This zonal connection worked well during most of the El Nino/Southern Oscillation (ENSO) events occurring after 1970; positive/negative SST anomalies in the eastern Pacific/Atlantic led to rainfall deficits over the whole West Africa. At low frequency time scale (periods greater than 8 years), positive SST anomalies in the Indian ocean and in equatorial Pacific existing after 1970 have been associated with decreasing rainfall intensity over West Africa through another zonal divergent circulation. These different time scales remote SST forcings are combined to provide a global zonal divergent circulation anomaly pattern which could explain the strong association between Sahel drought and ENSO dynamics after 1970.
\end{abstract}

\section{Introduction}

Sahel rainfall variability during the twentieth century has been connected to tropical Atlantic SST fields (Lamb 1978a,b) but also to global SST fields (Folland et al. 1986, Palmer 1986, Folland et al. 1991, Shinoda and Kawamura 1994). This connection is particularly strong at interdecadal time scale (Rowell et al. 1995): the long-term drying of Sahelian rainy season since the 50's can be associated with a long-term warming of SST in southern and equatorial oceans and in the whole Indian ocean, and with a long-term cooling of SST in northern oceans. However Rowell et al. (1995) pointed out a different correlation pattern related to connections between SST and Sahel rainfall at interannual time scale: the inter-decennal Atlantic meridional dipole is replaced at interannual timescale by negative correlations over the whole intertropical Atlantic basin, and negative correlations in the eastern equatorial Pacific are large. That means that ENSO events could be associated to Sahel droughts during northern summer with a specific dynamics at interannual time scale. Ward (1992) and Palmer et al. (1992) also pointed out the importance of ENSO forcing on interannual changes in the West African monsoon in recent years. In contrast several

Copyright 1996 by the American Geophysical Union.

Paper number $96 \mathrm{GL} 00246$

0094-8534/96/96GL-00246\$03.00 studies suggested that ENSO plays little or no role in West African precipitation (Stockenius 1981, Nicholson 1986, Ropelewsky and Halpert, 1987, 1989). This apparent lack of relationship between ENSO phenomenom and West African rainfall anomalies could be explained by the existence of periods of weak teleconnections and periods of strong one. Fig. 1 shows the time evolution of correlation coefficients between mean July-September Sahel rainfall index (combination of Continental and Atlantic Sahel indexes; Moron 1994) and the Southern Oscillation Index (SOI) computed with a twenty-year running window between 1945 and 1993. Local statistical significance levels have been established through Monte Carlo simulations taking into account the autocorrelation function (Janicot 1995), and the process of Livezey and Chen (1983) has been applied to determine the global levels of significance. The local 5\% significance level is indicated on Fig.1. The $5 \%$ global significance level related to the local 5\% significance level is passed when 7 correlation coefficients are greater than the local significance level. That is the case in Fig. 1 in particular for the final part of the curve between the periods 1968-87 and 1974-93. Then correlations between summer Sahel rainfall and Southern Oscillation indexes have been significant for the last twenty five years. How can such a long-term increase of correlation be explained ? We will answer to this question by considering global SST fields variability in connection with intertropical zonal divergent atmospheric circulations.

\section{Temporal Variability of SST Fields}

A principal component analysis of the covariance matrix of deseasonalised monthly SST departures has been performed on the UKMO $5^{\circ}$ lat./long. grid dataset

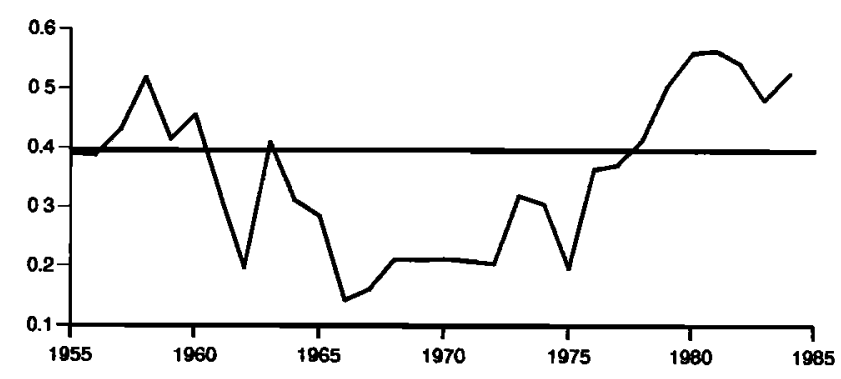

Figure 1. Time evolution of the correlations along the 1945-1993 period with a 20-year running window between Southern Oscillation Index and Sahel rainfall index in JulySeptember. 1970 for instance means period 1960-1979. The horizontal line represents the 5\% local statistical significance level according to Monte Carlo simulations. 

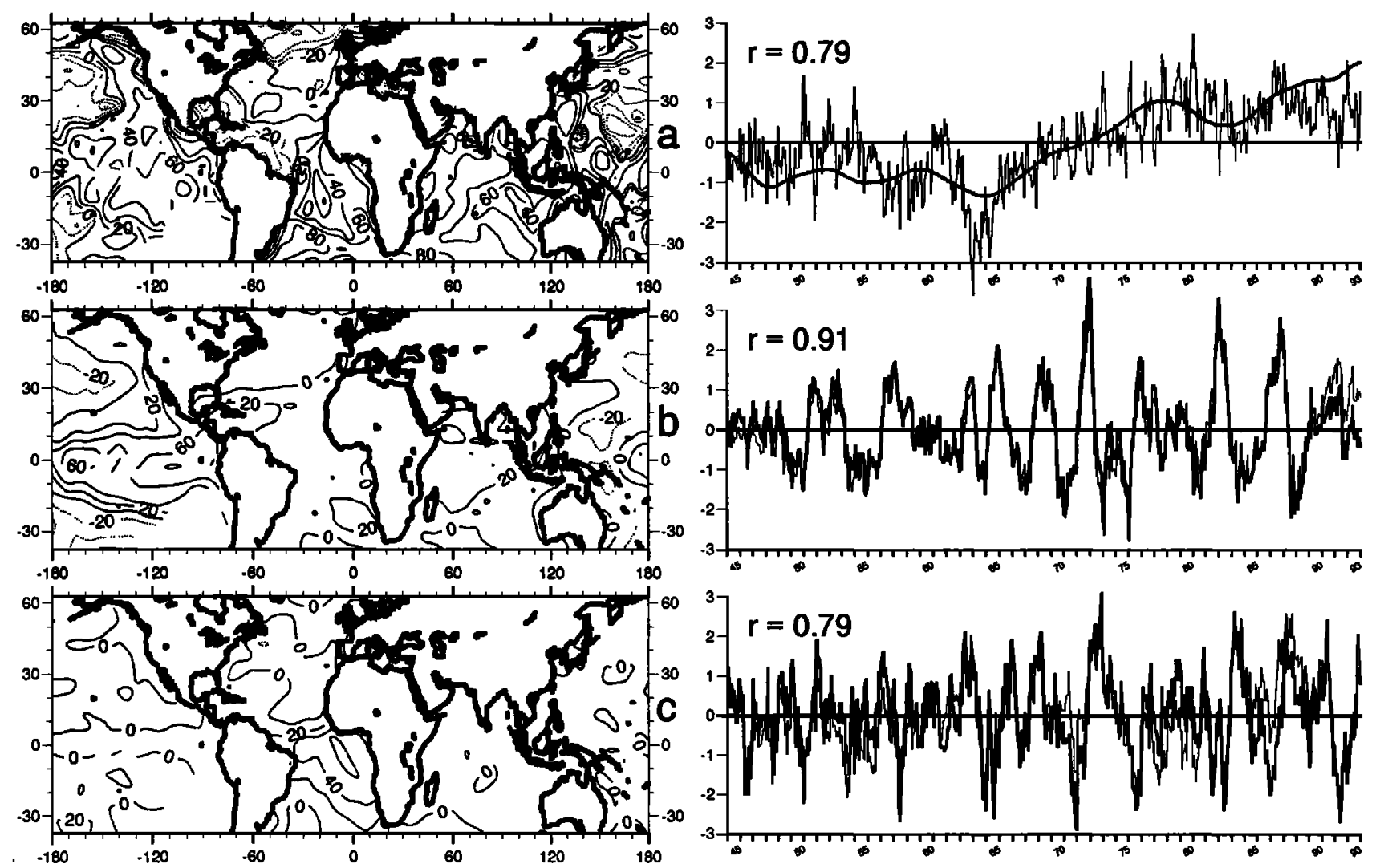

Figure 2. a) First Varimax principal component of low frequency filtered monthly deseasonalized SST anomalies (LF1) for 1945-1993; spatial loadings represent correlations between the eigenvector component series and the SST series; right: in thick line, standardized time series of component scores; in thin line, standardized time series of scores of the fourth Varimax principal component of unfiltered monthly deseasonalized SST anomalies (RPC4); correlation between the two series is indicated. b) Idem a) for the first Varimax principal component of high frequency filtered monthly deseasonalized SST anomalies (HF1) and for the standardized time series of scores of the first Varimax principal component of unfiltered monthly deseasonalized SST anomalies (RPC1; thin line). c) Idem a) for the fourth Varimax principal component of high frequency filtered monthly deseasonalized SST anomalies (HF4) and for the standardized time series of scores of the third Varimax principal component of unfiltered monthly deseasonalized SST anomalies (RPC3; thin line).

(Bottomley et al. 1990). A Varimax orthogonal rotation has been applied to define more physically coherent SST patterns (Janicot 1995). To investigate the long-term variation of Sahel rainfall - SOI correlation (Fig.1), spectral analyses have been performed on the first four SST rotated principal components and a threshold of 96 months ( 8 years) was pointed out between "low frequency" and "high frequency" variability. A low-pass Butterworth filter with a response of 0.5 at 90 months was applied to each grid-point SST time series to separate the low frequency signal from the residual one (high frequency). Then the same Varimax rotated principal component analysis has been applied separately on the low frequency and on the high frequency filtered SST datasets. At low frequency scale, the first rotated component (LF1; Fig.2a) explains $25 \%$ of low frequency filtered SST variance and displays positive weights in the Indian ocean, southern Atlantic, intertropical Pacific, and negative weights in extratropical northern Atlantic and extratropical northern and southern Pacific. The associated time series shows a reversal of sign at the beginning of the 70's, with negative values before and positive ones after. This component is highly correlated $(r=0.71)$ with the fourth Varimax unfiltered component
(RPC4; Fig.2a). RPC4 spatial pattern (not shown) has also largest loadings in the Indian ocean and in the extratropical northern and southern Atlantic but no weight in the Pacific. At high frequency scale, the first rotated component (HF1; Fig.2b) explaining $6.3 \%$ of high frequency filtered SST variance refers to El Nino / La Nina pattern with positive weights in the eastern equatorial Pacific and negative one to the west and in the extratropical Pacific. The associated time series reproduces quite well the El Nino and La Nina occurrences. This component is highly correlated with the first Varimax unfiltered component (RPC1; $r=0.91$ ) and their spatial patterns are very similar. To better focus on zonal intertropical atmospheric dynamics, the fourth high frequency filtered component (HF4; explains $2.3 \%$ of high frequency filtered SST variance; Fig.2c) has also been considered. The corresponding pattern shows high loadings in the equatorial and southern tropical Atlantic and characterizes warm and cold events in the Guinea Gulf. This component is highly correlated with the third Varimax unfiltered component ( $R P C 3 ; r=0.79$ ), their spatial patterns being very similar. The three filtered components LF1, HF1 and HF4 associated respectively with three "physical" unfiltered components RPC4, RPC1 and RPC3 enable to 
consider SST variability at two different time scales. Unfiltered RPCs will be used to compute new results and low and high filtered principal components will enable us to explain these results through an hypothesis dealing with global atmospheric patterns. RPC2 (positive weights in northern tropical and high latitudes Atlantic; not shown) will be also considered.

\section{Pacific-Atlantic Zonal Connection}

Tab. 1 shows the correlation coefficients in JulySeptember between rainfall indexes in Sahel and Guinea Coast regions (Moron 1994), and the rotated principal components RPC1, RPC3 and RPC4, for the periods 1945-1969, 1970-1993 and 1945-1993. The date of 1970 represents the beginning of the period with hightest correlations in Fig. 1 in concomitance with the sign reversal of the low frequency SST component LF1, and corresponds to the beginning of the long-term Sahel dry spell after the dry year of 1968 and the moderate one of 1969 . Correlation related to ENSO/LNSO (La Nina/Southern Oscillation) dynamics (RPC1) is negative with Sahel rainfall before $1970(-0.46)$ and increases in absolute value afterwards $(-0.66)$ in accordance to Fig.1. Related to Guinea Coast region, correlation is weak but changes from positive $(+0.37)$ to negative $(-0.23)$ values. On the other hand, related to SST variability in the equatorial and southern Atlantic (RPC3), correlation with Sahel rainfall has weakened drastically after 1970 (from -0.46 to +0.04 ) whereas it has remained high with Guinea Coast rainfall $( \pm 0.68$ and +0.58$)$. Then SST variability in the equatorial and southern Atlantic which has been shown to be associated with the latitudinal location of the ITCZ over West Africa (Shinoda and Kawamura 1994) is no more related to Sahel rainfall variability after 1970 . This is confirmed by computation of correlations between Sahel and Guinea Coast regions (Tab.1). Before 1970 the highly negative correlation $(-0.55)$ between these two regions corresponds to latitudinal variability of the ITCZ : when the ITCZ is located more northward (southward), Sahel rainfall anomaly is positive (negative) and Guinea Coast region rainfall anomaly is negative (positive). After 1970

Table 1. Correlations Between July-September Mean RPC1 to RPC4 and Rainfall Indexes in Sahel and Guinea Coast Regions for the Periods 1945-69, 1970-93 and 194593. RC3/2 Means RPC3 Minus RPC2. Statistical Significance Levels Have Been Computed With Monte Carlo Simulated Series Having the Same First Order Autocorrelation Coefficients Than the Tested Series. Italic/Underlined/Italic-Underlined Coefficients are Significant at a Level of $10 \% / 5 \% / 1 \%$.

\begin{tabular}{lcccccc}
\hline & Sahel & Sahel & Sahel & Guinea & Guinea & Guinea \\
& $45-69$ & $\mathbf{7 0 - 9 3}$ & $45-93$ & $45-69$ & $70-93$ & $45-93$ \\
\hline RPC1 & $\underline{-0.46}$ & $\underline{-0.66}$ & $\underline{-0.43}$ & +0.37 & -0.23 & +0.07 \\
RPC2 & +0.40 & -0.08 & +0.24 & -0.23 & +0.38 & +0.05 \\
RPC3 & $\underline{-0.46}$ & +0.04 & -0.37 & +0.68 & +0.58 & +0.49 \\
RPC4 & $\underline{+0.11}$ & -0.17 & $\underline{-0.52}$ & -0.21 & +0.02 & -0.19 \\
RC3/2 & $\underline{-0.60}$ & +0.11 & $\underline{-0.48}$ & +0.61 & +0.25 & $\underline{+0.36}$ \\
Guinea & $\underline{-0.55}$ & +0.06 & -0.13 & & & \\
\hline
\end{tabular}

there is no more significant correlation $(+0.06)$ between rainfall anomalies of these two regions. This is also consistent with the connection decrease between rainfall indexes and RPC3 minus RPC2 index (Tab.1) which describes intertropical Atlantic SST dipole. Considering ENSO events after 1970, most of them $(1972,1976,1982$, $1983,1992,1993$ ) occurred with negative or slightly positive mean July-September SST anomalies in the Guinea Gulf, and were associated with West African rainfall deficits. Opposite SST patterns have been also observed during most of LNSO events $(1970,1973,1988)$ which were associated with more rainy monsoon seasons (Janicot 1994). However the ENSO event of 1987 , concomitant with highly positive mean July-September SST anomalies in the Guinea Gulf was associated with Sahel rainfall deficit and positive rainfall anomalies in the Guinea Coast region. Then after 1970, not only warmer than usual SST in the Guinea Gulf but also colder than usual SST can be associated with Sahel drought, which is in accordance to the low correlation $(+0.04)$ shown in Tab. 1 between Sahel rainfall and RPC3 values. These associations between ENSO/LNSO events and West African rainfall anomaly patterns combined with cold/warm events in the Guinea Gulf have been confirmed by a general circulation model experiment (Janicot 1994): in case of ENSO (LNSO) event occurring after 1970, an Atlantic zonal divergent circulation was pointed out with ascending (subsiding) branch over the eastern intertropical Pacific and subsiding (ascending) one over the Guinea Gulf and West Africa, except in 1987 where RPC1 and RPC3 were both positive; then the simulated zonal atmospheric coupling, controled by the difference between RPC3 and RPC1, was weak and West African monsoon dynamics was controled by highly positive SST anomalies in the Gulf of Guinea which led to Sahel rainfall deficit and positive rainfall anomalies in Guinea Coast region, a pattern related to a southward location of the ITCZ (Janicot 1994).

\section{Global Zonal Connections}

Shinoda and Kawamura (1994) suggested another kind of zonal atmospheric connection between SST field and West African rainfall in August. They decomposed the West African rainfall field by defining the latitude of the center of gravity of the rainbelt and the rainfall intensity inside the rainbelt. The latitude of the center of gravity has shown large interannual variability since 1950 , while rainfall intensity inside the rainbelt depicted a large negative linear trend since 1960. Over the period 1946-1988, the latitude of the center of gravity has been negatively correlated with RPC3 at interannual scale, and the rainfall intensity inside the rainbelt has been negatively correlated with RPC4 but at inter-decadal time scale only (this is consistent with the high correlation in Tab. $1, \underline{-0.52}$, observed between RPC4 and Sahel rainfall index for the period 1945-93 only). They argued that at inter-decadal scale the warming of Indian ocean could lead to the decreasing rainfall intensity in the rainbelt by forcing a zonal divergent atmospheric circulation with upward motions over the Indian basin and subsidence over West Africa. Their hypothesis was confirmed by a correlation analysis with $700 \mathrm{hPa}$ heights. Let us consider combinations of LF1 and HF1. For an ENSO occurrence (positive HF1) embedded in the global 


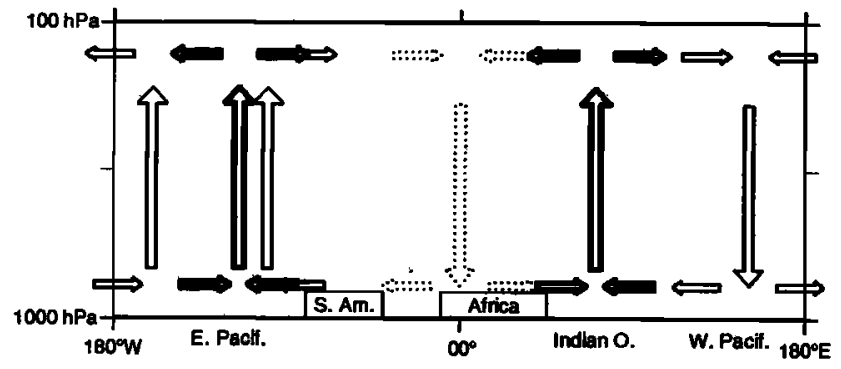

Figure 3. Longitude cross-section of a schematic zonal divergent atmospheric circulation anomaly pattern in the intertropical band controled by a global scale SST forcing combining positive contributions of LF1 and HF1 SST components and negative contribution of HF4 SST component. Thick/thin/dashed arrows indicate divergent atmospheric circulation anomalies resulting from LF1/HF1/HF4 SST forcing.

scale SST anomaly pattern of the 70's or the 80's (positive LF1), SST will increase in the Indian ocean (through LF1), in the eastern equatorial Pacific (through both HF1 and LF1) and SST will decrease in the western Pacific (through HF1). Then the zonal divergent atmospheric circulation anomaly over the Pacific and a reversed zonal divergent circulation anomaly between the western Pacific and the Indian ocean will be enhanced (Fig.3). The SST pattern tends to induce two other zonal divergent atmospheric circulation anomalies, first between Indian ocean and the eastern equatorial Atlantic, second between eastern Pacific and the eastern equatorial Atlantic. This pattern leads to zonal wind convergence in the upper troposphere and subsiding motions over the Guinea Gulf and West Africa in particular when negative SST anomalies occur in the eastern equatorial Atlantic (negative HF4; Fig.3), in accordance to rainfall deficit over the whole West Africa. This could have been the case for the ENSO events of 1972, 76, 82, 83, 92 and 93, when connections between the Southern Oscillation and Sahel rainfall could have been enhanced by the global scale SST anomaly pattern. On the other hand if we consider an ENSO event (positive HF1) in the 50's or the 60's (negative LF1), the reversal of the zonal divergent circulation anomalies forced by LF1 (thick arrows in Fig.3) will tend to disrupt the global atmospheric dynamics and to decrease the atmospheric connections between the Southern Oscillation and Sahel rainfall. Then the long-term increase of correlation between SOI and Sahel rainfall index since the late 60's (Fig.1) could result mainly from a long-term "power increase" of SST in the Indian ocean and in the intertropical Pacific.

\section{References}

Bottomley, M., C.K. Folland, J. Hsiung and D.E. Parker, Global ocean surface temperature atlas, Meteor. Office and Mass. Instit. of Tech., 313 plates, 1990.

Folland, C.K., T.N. Palmer and D.E. Parker, Sahel rainfall and worldwide sea temperature 1901-1985, Nature, 320, 602607,1986

Folland, C.K., J.A. Owen, M.N. Ward and A.W. Colman, Prediction of seasonal rainfall in the Sahel region using empirical and dynamical methods, Jour. of Forecasting, 10, 21-56, 1991.

Janicot, S., The West African monsoon of 1987 and 1988 : Pacific or Atlantic signal ?, Proc. Intern. Conf. on monsoon variability and prediction, WCRP-84,WMO/TD-N ${ }^{\circ} 619$, 765-772, 1994.

Janicot, S., Global sea surface temperature variability associated with West African rainfall anomaly types. Application to seasonal forecast of Sahel rainfall, Proc. $6^{\text {th }}$ Int. Meeting on Statistical Climatology, 483-486, 1995.

Lamb, P.J., Case studies of tropical Atlantic surface circulation patterns during recent sub-Saharan weather anomalies: 1967 and 1968, Mon. Wea. Rev., 106, 482-491, 1978a.

Lamb, P.J., Large scale tropical surface circulation patterns associated with Subsaharan weather anomalies, Tellus, 30 , 240-251, 1978b.

Livezey, R.E. and W.Y. Chen, Statistical field significance and its determination by Monte Carlo techniques, Mon. Wea. Rev., 111, 46-59, 1983.

Moron, V., Guinean and Sahelian rainfall anomaly indices at annual and monthly time scales (1933-1990), Int. J. Climatol., 14, 325-341, 1994.

Nicholson, S.E., The quasi-periodic behavior of rainfall variability in Africa and its relationship to the Southern Oscillation, Arch. Met. Geoph. Biocl., Ser.A 34, 311-348, 1986.

Palmer, T.N., Influence of the Atlantic, Pacific, and Indian oceans on Sahel rainfall, Nature, 322, 251-253, 1986.

Palmer, T.N., C. Brankovic, P. Viterbo and M.J. Miller, Modeling interannual variations of summer monsoons, $J$. Climate, 5, 399-417, 1992.

Ropelewsky, C.F. and M.S. Halpert, Global and regional scale precipitation and temperature patterns associated with El Nino/Southern Oscillation, Mon. Wea. Rev., 115, 16061626, 1987.

Ropelewsky, C.F. and M.S. Halpert, Precipitation patterns associated with the high index phase of the Southern Oscillation, J. Climate, 2, 268-284, 1989.

Rowell, D.P., C.K. Folland, K. Maskell and M.N. Ward, Variability of summer rainfall over tropical North Africa (1906-1992): observations and modelling, Quart. J. Roy. Met. Soc., 121, 669-704, 1995.

Shinoda, M. and R. Kawamura, Tropical rainbelt, circulation and sea surface temperatures associated with the Sahelian rainfall trend, J. Meteo. Soc. Japan, 72, 341-357, 1994.

Stockenius, T., Interannual variations of tropical precipitation patterns, Mon. Wea. Rev., 109, 1233-1247, 1981.

Ward, M.N., Provisionally corrected surface wind data, worldwide ocean-atmosphere surface fields, and Sahelian rainfall variability, J. Climate, 5, 454-475, 1992.

S. Janicot, Laboratoire de Météorologie Dynamique, Ecole Polytechnique, 91128 Palaiseau cedex, France (e-mail: janicot@lmd.ens.fr)

V. Moron and B. Fontaine, Centre de Recherches de Climatologie, Université de Bourgogne, Faculté des Sciences Gabriel, BP 138, 21004 Dijon cedex, France (e-mail: raoult@satie.u-bourgogne.fr; fontaine@satie.u-bourgogne.fr)

(Received October 13, 1995; accepted November 29, 1995.) 